\title{
Sequence variations in the collagen IX and XI genes are associated with degenerative lumbar spinal stenosis
}

\author{
N Noponen-Hietala, E Kyllönen, M Männikkö, E Ilkko, J Karppinen, J Ott, L Ala-Kokko
}

See end of article for authors' affiliations

\section{Correspondence to:} Professor L Ala-Kokko, Center for Gene Therapy, Tulane University Health Sciences Center, 1430 Tulane Avenue, SL-99, New Orleans, LA 70112 USA; lalako@tulane.edu

Accepted 20 May 2003

\begin{abstract}
Background: Degenerative lumbar spinal stenosis (LSS) is usually caused by disc herniation or degeneration. Several genetic factors have been implicated in disc disease. Tryptophan alleles in COL9A2 and COL9A3 have been shown to be associated with lumbar disc disease in the Finnish population, and polymorphisms in the vitamin D receptor gene (VDR) (Fokl and Taql), the matrix metalloproteinase-3 gene (MMP-3) and an aggrecan gene (AGC1) VNTR have been reported to be associated with disc degeneration. In addition, an IVS6-4 a > t polymorphism in COL1 1A2 has been found in connection with stenosis caused by ossification of the posterior longitudinal ligament in the Japanese population.

Objective: To study the role of genetic factors in LSS.

Methods: 29 Finnish probands were analysed for mutations in the genes coding for intervertebral disc matrix proteins, COL1A1, COL1A2, COL2A1, COL9A1, COL9A2, COL9A3, COL11A1, COL11A2, and $A G C 1$. VDR and MMP-3 polymorphisms were also analysed. Sequence variations were tested in 56 Finnish controls.

Results: Several disease associated alleles were identified. A splice site mutation in COL9A2 leading to a premature translation termination codon and the generation of a truncated protein was identified in one proband, another had the Trp2 allele, and four others the Trp3 allele. The frequency of the COL1 1A2 IVS6 ${ }^{-4}$ t allele was $93.1 \%$ in the probands and $72.3 \%$ in controls $(p=0.0016)$. The differences in genotype frequencies for this site were less significant $(p=0.0043)$.

Conclusions: Genetic factors have an important role in the pathogenesis of LSS.
\end{abstract}

S pinal stenosis (MIM 152550) is defined as a narrowing of the spinal canal, nerve root canals, or intervertebral foramina. It can be congenital or acquired. ${ }^{1}$ Congenital stenosis is due to an idiopathic developmental narrowing of the spinal canal, typically associated with achondroplasia (MIM 100800) and hypochondroplasia (MIM 146000), ${ }^{2-4}$ while acquired or degenerative stenosis is usually caused by disc herniation or degenerative changes in the intervertebral discs, facet joints, and ligamentum flavum, but may also be caused by spondylolisthesis, tumours, Paget's disease or ossification of the posterior longitudinal ligament (OPLL) of the spine. ${ }^{1356}$ Although congenital stenosis is rare, degenerative stenosis is one of the most common clinically important spinal disorders in the aging population. ${ }^{3}$

Lumbar spinal stenosis (LSS) typically affects subjects over 50 years of age, with a prevalence of $1.7-10 \% .^{78}$ Symptoms can be unilateral or bilateral and can include pseudoclaudication, low back pain, numbness, weakness, and pain on extension of the lumbar spine, ${ }^{3-11}$ and can generally be relieved by flexing of the lumbosacral spine. ${ }^{39}$ The correlation of radiographic abnormalities with clinical findings and signs is extremely important for establishing the diagnosis. ${ }^{3}{ }^{10}$

Because congenital stenosis is typically associated with chondrodysplasias, which are genetic disorders, it is possible that genetic factors may also play a part in degenerative stenosis. This hypothesis is supported by various findings. Varughese and Quartey reported a case of four brothers with lumbar disc herniation associated with narrowing of the lumbar spinal canal. ${ }^{12}$ OPLL is a leading cause of spinal stenosis in the Japanese, with a prevalence of $1.9-4.3 \% .^{5} \mathrm{~A}$ linkage was identified between OPLL and chromosome $6 \mathrm{p},{ }^{6} \mathrm{a}$ region containing the gene for the $\alpha 2$ chain of collagen XI, COL11A2, and an allelic association has been reported between OPLL and a COL11A2 polymorphism, IVS6 $^{-4}$ a>t. ${ }^{6}{ }^{13}$ In addition, tryptophan alleles in COL9A2 (Trp2 $)^{14}$ and COL9A3 $(\operatorname{Trp} 3)^{15}$ have been shown to be associated with lumbar disc disease (LDD) in the Finnish population. Likewise, a heterozygous mutation resulting in haploinsufficiency of the aggrecan gene, AGCl was found to lead to intervertebral disc herniation and degeneration in mice, ${ }^{16}$ and an association between a VNTR in AGCl and lumbar disc degeneration was subsequently reported in humans. ${ }^{17}$ Polymorphisms in the vitamin D receptor gene, VDR, ${ }^{18-20}$ and the matrix metalloproteinase- 3 gene, MMP- $3,{ }^{21}$ have also been shown to be associated with intervertebral disc degeneration.

In view of the evidence for the contribution of genetic factors to lumbar disc disease, disc degeneration and OPLL, we analysed 29 probands with degenerative LSS for sequence variations in nine candidate genes coding for intervertebral disc matrix proteins: COLlAl, COL1A2, COL2Al, COL9Al, COL9A2, COL9A3, COLllAl, COLllA2, and AGC1. In

Abbreviations: $\mathrm{AGCl}$, gene coding for aggrecan; $\mathrm{COL1Al}$ and COL1A2, genes coding for collagen $|\alpha|$ and $\alpha 2$ chains; COL2A l, gene coding for collagen II $\alpha 1$ chain; COL9A1, COL9A2, and COL9A3, genes coding for collagen IX $\alpha 1, \alpha 2$, and $\alpha 3$ chains; COLIIAI and COL1 1A2, genes coding for collagen XI $\alpha 1$ and $\alpha 2$ chains; IVS, noncoding intronic sequence located between coding sequences; CS, chondroitin sulphate; CSGE, conformation sensitive gel electrophoresis; CT, computed tomography; LDD, lumbar disc disease; LSS, lumbar spinal stenosis; MMP, matrix metalloproteinase; MRI, magnetic resonance imaging; OLF, ossification of the ligamentum flavum; OPLL, ossification of the posterior longitudinal ligament; $\mathrm{PCR}$, polymerase chain reaction; RT, reverse transcriptase; SNP, single nucleotide polymorphism; VDR, vitamin D receptor gene; VNTR, variable number of tandem repeats 
addition, two single nucleotide polymorphisms (SNP) in VDR and one in MMP-3 were analysed.

\section{MATERIALS AND METHODS \\ Subjects}

Twenty nine consecutive Finnish probands (14 male, 15 female) aged from 42 to 75 years (mean 59) with symptoms consistent with LSS were included in the study. The probands were from the Department of Physical Medicine and Rehabilitation, Oulu University Hospital (Oulu, Finland). The symptoms consisted of self reported pseudoclaudication, stenotic symptoms extending to the lower extremities upon extension of the lumbar spine, or numbness or weakness of the lower extremities. The probands were examined clinically and radiologically to confirm the degenerative nature of the stenosis.

Neurological examination included an evaluation of motor reflexes in the lower extremities. Peripheral pulses were evaluated to exclude vascular claudication. The magnetic resonance imaging (MRI) examinations, performed with a 1.5 T scanner (Signa, GE Medical systems), consisted of $\mathrm{T}_{2}$ weighted sagittal fast spin echo images with a repetition time/echo time of 4000/95 ms and a slice thickness of $4 \mathrm{~mm}$. $\mathrm{T}_{1}$ weighted $(580 / 15 \mathrm{~ms})$ sagittal spin echo images and transaxial $\mathrm{T}_{2}$ weighted $(6000 / 105 \mathrm{~ms})$ fast spin echo images were taken, also with a slice thickness of $4 \mathrm{~mm}$. The transaxial MRI images consisted of scans through the L2 to SI interspaces, and the CT images (Hi Speed Advantage, GE Medical Systems) of scans through the same interspaces with a slice thickness of $4 \mathrm{~mm}$. MRI scans were obtained for all the probands and computed tomography (CT) scans for 25 of the 29 probands (table 1 ).

The degrees of stenosis, degeneration, and end plate changes were evaluated from the MRI scans. Stenosis was graded as 0 (no stenosis), grade 1 (mild to moderate) if the sagittal diameter of the dural sac at the disc level was from 5 to $10 \mathrm{~mm}$, and grade 2 (severe) if the diameter was $<5 \mathrm{~mm}$.
Degeneration was evaluated from the $\mathrm{T}_{2}$ weighted sagittal scans and classified as 0 (no signal changes), 1 (slight decrease in signal intensity in the nucleus), 2 (hypointense nucleus pulposus with normal disc height), and 3 (hypointense nucleus with disc space narrowing). End plate changes were graded according to the criteria of Modic et al. $^{22}$ Ossification of the ligamentum flavum (OLF) was evaluated from the CT scans, on the basis of hyperdense calcified areas in the ligamentum, and OPLL as local calcification on the CT and MRI scan and a hypointense hypertrophic band at the posterior edge of the vertebral body on the $\mathrm{T}_{2}$ weighted sagittal MRI scan. All the MRI and CT scans were read by two experienced doctors who were unaware of the results of the genetic analysis and of the clinical history and physical status of the probands. Those responsible for the clinical assessments were also unaware of the results of the genetic analysis.

The control set consisted of 56 subjects aged 22-72 years (mean 43) with no history of back problems. The control set for the AGCl VNTR comprised 153 subjects aged 4045 years with no history of back problems. All controls were Finnish and they were from the same region as the probands.

The study was approved by the local ethics committees. signed informed consent was obtained from all the subjects.

\section{DNA analysis}

Genomic DNA extracted from the blood samples was used as a template for the polymerase chain reaction (PCR). Exons and exon boundaries of COLlAl, COLlA2, COL2Al, COL9A1, COL9A2, COL9A3, COL11A1, COL11A2, and AGC1 (table 2) were amplified by PCR and analysed by conformation sensitive gel electrophoresis (CSGE) as previously described. ${ }^{35}$ The PCR products that contained heteroduplexes were sequenced with an ABI PRISM 3100 sequencer and BigDye Terminator Sequencing Kit (Applied Biosystems) to define the underlying sequence variations.

Table 1 Clinical and radiological findings of the probands

\begin{tabular}{|c|c|c|c|c|c|c|c|c|}
\hline \multirow[b]{2}{*}{ Proband (sex) } & \multirow[b]{2}{*}{ Age (years) } & \multirow{2}{*}{$\begin{array}{l}\text { Self reported } \\
\text { walking distance } \\
\text { (m) }\end{array}$} & \multicolumn{5}{|c|}{ Radiological findings } & \multirow{2}{*}{$\begin{array}{l}\text { Decompressive } \\
\text { operation }\end{array}$} \\
\hline & & & Stenosis* & Disc degeneration & Modic's criteriał & OPLL & OLF & \\
\hline $1(M)$ & 65 & 100 & $0-0-1-1-0$ & $1-2-2-3-3$ & $0-0-1-2-2$ & + & - & + \\
\hline $2(F)$ & 64 & 100 & $0-1-1-0-0$ & $2-2-3-3-3$ & $2-2-2-2-2$ & + & + & $+\S$ \\
\hline $3(M)$ & 75 & 200 & $0-0-0-1-0$ & $2-2-3-3-3$ & $0-0-2-0-0$ & - & NA $\ddagger$ & - \\
\hline $4(F)$ & 50 & 200 & $0-0-2-2-0$ & $2-2-2-3-3$ & $0-0-0-2-2$ & - & + & + \\
\hline $5(M)$ & 74 & 200 & $0-0-1-2-0$ & $2-2-2-3-2$ & $0-0-0-0-0$ & - & + & - \\
\hline $6(M)$ & 54 & 3000 & $0-2-2-2-0$ & $2-2-3-2-3$ & $0-0-0-0-0$ & - & - & - \\
\hline $7(M)$ & 52 & 500 & $0-1-2-0-0$ & $0-2-2-2-1$ & $0-0-2-2-0$ & - & - & - \\
\hline $8(M)$ & 72 & 50 & $0-0-2-2-1$ & $3-3-3-3-3$ & $2-2-2-2-2$ & + & + & - \\
\hline $9(F)$ & 45 & 2000 & $0-0-1-0-0$ & $0-2-2-3-3$ & $0-0-0-0-0$ & - & - & + \\
\hline $10(\mathrm{~F})$ & 75 & 100 & $0-0-2-2-0$ & $2-3-2-3-2$ & $2-2-2-2-2$ & + & NA $\ddagger$ & - \\
\hline 11 (F) & 50 & 2000 & $0-0-0-1-0$ & $3-3-3-3-0$ & $0-0-0-0-0$ & - & - & + \\
\hline 12 (M) & 54 & 50 & $0-0-1-0-1$ & $0-2-2-3-2$ & $0-0-0-2-0$ & - & NA $\ddagger$ & + \\
\hline $13(F)$ & 64 & 300 & $0-0-0-0-0$ & $2-2-3-3-2$ & $0-0-0-0-2$ & - & - & + \\
\hline $14(\mathrm{~F})$ & 67 & 200 & $0-0-2-2-0$ & $2-3-3-2-2$ & $0-2-0-0-0$ & - & - & + \\
\hline $15(F)$ & 42 & 2000 & $0-0-0-0-1$ & $1-1-1-1-3$ & $0-0-0-0-2$ & - & + & - \\
\hline $16(F)$ & 65 & 500 & $0-0-1-2-0$ & $2-2-3-3-2$ & $0-0-0-2-0$ & + & - & - \\
\hline $17(F)$ & 45 & 100 & $0-0-0-1-0$ & $1-1-3-3-3$ & $0-0-0-0-2$ & - & - & - \\
\hline $18(\mathrm{M})$ & 53 & 50 & $0-1-2-1-0$ & $0-1-3-3-3$ & $0-0-0-0-0$ & - & + & + \\
\hline $19(\mathrm{~F})$ & 53 & 100 & $0-0-1-0-0$ & $0-0-2-2-3$ & $0-0-0-0-0$ & - & - & - \\
\hline 20 (M) & 47 & 500 & $0-0-0-1-0$ & $1-0-0-3-3$ & $0-0-0-0-2$ & - & + & $+\S$ \\
\hline 21 (M) & 56 & 100 & $0-0-1-0-0$ & $0-2-2-2-0$ & $0-0-0-0-0$ & - & - & + \\
\hline $22(F)$ & 50 & 3000 & $0-0-2-0-0$ & $3-3-3-2-2$ & $0-2-2-1-0$ & - & - & - \\
\hline 23 (F) & 55 & 50 & $0-0-0-1-0$ & $2-2-2-2-2$ & $0-0-0-0-0$ & - & NA $\ddagger$ & - \\
\hline $24(F)$ & 64 & 3000 & $0-0-1-0-0$ & $1-1-1-3-3$ & $0-0-0-2-2$ & - & - & $+\S$ \\
\hline 25 (M) & 61 & 200 & $0-0-0-2-0$ & $1-1-2-1-3$ & $0-0-0-2-2$ & - & - & - \\
\hline 26 (M) & 60 & 1000 & $0-0-1-1-0$ & $1-2-2-3-1$ & $0-0-0-2-0$ & - & - & - \\
\hline 27 (M) & 56 & 200 & $0-0-1-0-0$ & $0-1-1-0-3$ & $0-0-0-0-2$ & - & - & - \\
\hline 28 (M) & 70 & 50 & $0-0-1-0-0$ & $1-3-3-3-3$ & $0-2-0-2-2$ & - & - & + \\
\hline $29(\mathrm{~F})$ & 65 & 50 & $0-0-0-1-0$ & $1-1-1-3-2$ & $0-0-0-0-0$ & + & + & + \\
\hline
\end{tabular}

*The first number corresponds to L1-2 and the last to L5-S1; †Modic et al, 1988; †not analysed; §operated on herniated nucleus pulposus. 


\begin{tabular}{llll} 
Table 2 & \multicolumn{3}{l}{ Genes and polymorphisms analysed } \\
\hline Gene & Region analysed & Detection method & References \\
\hline COL1A1 & Exons 1-52 & CSGE & 23 \\
COL1A2 & Exons 1-52 & CSGE & 23 \\
COL2A1 & Exons 1-52 & CSGE & 24 \\
COL9A1 & Exons 1-38 & CSGE & 25 \\
COL9A2 & Exons 1-32 & CSGE & 25 \\
COL9A3 & Exons 2-32 & CSGE & 26 \\
COL11A1 & Exons 1-68 & CSGE & 27 \\
COL11A2 & Exons 1-66 & CSGE & 28 \\
AGC1* & Exons 2-19, & CSGE, Southern & $29,30,31$ \\
& exon 12, VNTR & & \\
VDR & $352 T>C \dagger$ & Taql digestion, & 32 \\
& $2 T>C \dagger$ & Fokl digestion & 33 \\
MMP-3 & $-1171 \Delta$ a & Sequencing & 34 \\
\hline
\end{tabular}

*Exons 2 to 11 , part of exon 12, and exons 13 to 19 were analysed by CSGE. The VNTR region in exon 12 was analysed by Southern hybridisation; ffrom the start of translation; ffrom the start of transcription.

\section{RNA analysis}

Total RNA for proband 23 and a control subject was extracted from Epstein-Barr virus-transformed lymphoblasts. The cDNA synthesis was carried out with the Superscript First Strand Synthesis System for reverse transcriptase (RT)-PCR (Invitrogen, Carlsbad, CA, USA) and followed by amplification with two sets of PCR primers. The first PCR was performed with a pair of primers that corresponded to exons 23 and 30 (5'-CAA GGC GAG AGG GGT CCA GTG and 5'CAC GGC GAC CTC TGC CAG TTG C) of COL9A2, and the second with a pair that corresponded to exons 24 and 29 (5' GCT TGC CAG GCG TCA AAG GAG and 5'- CAG CAT CTT CAG CGC CAC ATC). The primer pairs for the COL1 1A2 CDNA analysis corresponded to exons 5 and 9, the pair used for the first amplification being 5'-CAT GTG AAC AGA AGG AGC TGG A and 5'-AGG TTC CAA CAC TGC AGG CTC and the nested pair 5'-CAT CAA GAC TTC ACA GGC CAC AA and 5' CTT TCT CTC CCT TCA GCC CTC GG. The amplifications were carried out in a volume of $25 \mu \mathrm{l}$ containing $1 \mu \mathrm{l}$ of the cDNA, 7.5 pmol of each primer, $1.5 \mathrm{mM} \mathrm{MgCl}_{2}, 0.2 \mathrm{mM}$ dNTPs, and 1.5 U AmpliTaq gold DNA polymerase. The conditions, after an initial denaturation at $95^{\circ} \mathrm{C}$ for 12 minutes, were 34 cycles of 30 seconds at $95^{\circ} \mathrm{C}, 30$ seconds at $60^{\circ} \mathrm{C}$ and 30 seconds at $72^{\circ} \mathrm{C}$, followed by a final extension at $72^{\circ} \mathrm{C}$ for 8 minutes. The products were analysed on agarose gels and by sequencing.

\section{Southern analysis of the AGC1 VNTR}

A probe for the AGCl VNTR in exon 12 was generated by PCR. ${ }^{31}$ The PCR was carried out with the Advantage-GC Genomic PCR kit (Clontech, Palo Alto, CA, USA) with $0.5 \mathrm{M}$ of GC-melt mix. The PCR product was analysed on agarose gel, purified from the gel (Qiaex II Gel Extraction Kit, Qiagen, Valencia, CA, USA), cloned, and sequenced using the ABI PRISM 377 Sequencer (Applied Biosystems). The clone was digested with EcoRI, and labelled with $\left[{ }^{32} \mathrm{P}\right] \mathrm{dCTP}$ using the Rediprime II DNA labelling system (Amersham Pharmacia Biotech, Piscataway, NJ, USA).

VNTR polymorphism was analysed by Southern hybridisation. ${ }^{31}$ Five $\mu \mathrm{g}$ of genomic DNA was digested with HaeIII and separated on a $1.2 \%$ agarose gel for 20 hours at $45 \mathrm{~V}$. A molecular weight marker, a 100 bp DNA step ladder (Promega, Madison, WI, USA), was added to each gel. The size of one repeat was $57 \mathrm{bp}$. The number of repeats for each sample was estimated from the sizes of the fragments observed in Southern analysis.

\section{Analysis of VDR and MMP-3 polymorphisms}

Two intragenic polymorphisms, $\mathrm{T}$ to $\mathrm{C}$ in exon $9^{18}$ and $\mathrm{T}$ to $\mathrm{C}$ at the translation initiation codon ${ }^{36}{ }^{37}$ in VDR were analysed as previously described. Exon $9 \mathrm{~T}$ to $\mathrm{C}$ polymorphism was detected by TaqI restriction enzyme digestion. The alleles were named $\mathrm{T}$ and $\mathrm{t}$, the capital denoting absence of the TaqI site or nucleotide $\mathrm{T}$. The $\mathrm{T}$ to $\mathrm{C}$ polymorphism at the translation initiation codon (ATG/ACG) of VDR was determined using the FokI restriction enzyme. Allele $\mathrm{F}$ indicates the presence of nucleotide $\mathrm{C}$, which results in the absence of the first translation initiation codon, and use of the second methionine codon located three amino acids downstream. ${ }^{36} 37$

A 179 or 180 bp region of the MMP-3 promoter containing a $5 \mathrm{a} / 6 \mathrm{a}$ polymorphism was determined by sequencing (table 2). ${ }^{21}$

\section{Statistical analysis}

To test the equality of the allele frequencies between the probands with LSS and controls, $\chi^{2}$ tests were carried out for $2 \times 2$ tables of allele counts. Haplotype frequencies for four marker loci, COLl1A2 IVS6 ${ }^{-4}$, VDR (FokI and TaqI), and MMP-3 polymorphisms, were estimated with the snphap program, which applies maximum likelihood estimation via a so-called EM algorithm. ${ }^{38}$ A likelihood ratio test was employed to test for differences in these frequencies between the probands and controls.

\section{RESULTS}

\section{Clinical and radiological findings}

All 29 probands with degenerative LSS who were examined clinically and radiologically had a self reported limitation in walking distance (range 50-3000 $\mathrm{m}$, table 1) and at least one other stenotic symptom (pain or numbness of the lower extremities upon extension of the lumbar spine, or numbness or weakness in the lower extremities). The clinical findings showed seven probands with bilateral tendon reflex defects in the lower extremities, but none had objective muscle weakness or peripheral pulse abnormalities. Twelve probands had undergone a decompressive operation. In addition, three (Nos 2, 20, and 24) had previously been operated on for a herniated nucleus pulposus and were found to have a stenosis at a different lumbar level (table 1).

Radiological evaluation of the lumbar region indicated that every proband, except for No 13, who had undergone decompressive surgery for stenosis before inclusion in the study, had stenosis at least at one level (table 1). Severe disc degeneration (grade 2 or 3 ) was also seen in every proband at least at one lumbar level (table 1, figs 1A, B, and C). Twenty probands had grade 2 end plate degeneration according to Modic's criteria (table 1, figs $\mathrm{IA}$ and $\mathrm{BB}$ ), six had OPLL (table 1, fig 1B), and eight were found to have OLF (table 1).

\section{DNA analysis of collagen genes and AGC 1}

The probands were analysed for mutations in COLlAl, COLlA2, COL2Al, COL9A1, COL9A2, COL9A3, COL11Al, COL11A2, and AGCl (table 2).

Analysis of the collagen IX genes, COL9Al, COL9A2 and COL9A3, showed three interesting changes (table 3): an a to c change in COL9A2 IVS26 ${ }^{-2}, \operatorname{Gln}^{326}$ to Trp (Trp2 allele) in the $\alpha 2$ (IX) chain, ${ }^{14}$ and $\operatorname{Arg}^{103}$ to Trp (Trp3 allele) in the $\alpha 3$ (IX) chain. ${ }^{15}$ Proband 23 (table 1) had the a to c mutation in COL9A2 IVS $26^{-2}$. This mutation was not found in the controls. Total RNA was isolated from the lymphoblasts of proband 23 and analysed by RT-PCR for possible splicing defects, resulting in the identification of two products, of about 550 bp and 460 bp with the primer set for exons 23-30, and of about 430 and $340 \mathrm{bp}$ with the primer set for exons 24-29 (fig 2). Sequencing indicated that the smaller product contained only the wild-type sequence, while the larger product contained the wild-type sequence and sequences for the entire intron 26 (not shown). The mutation prevented 

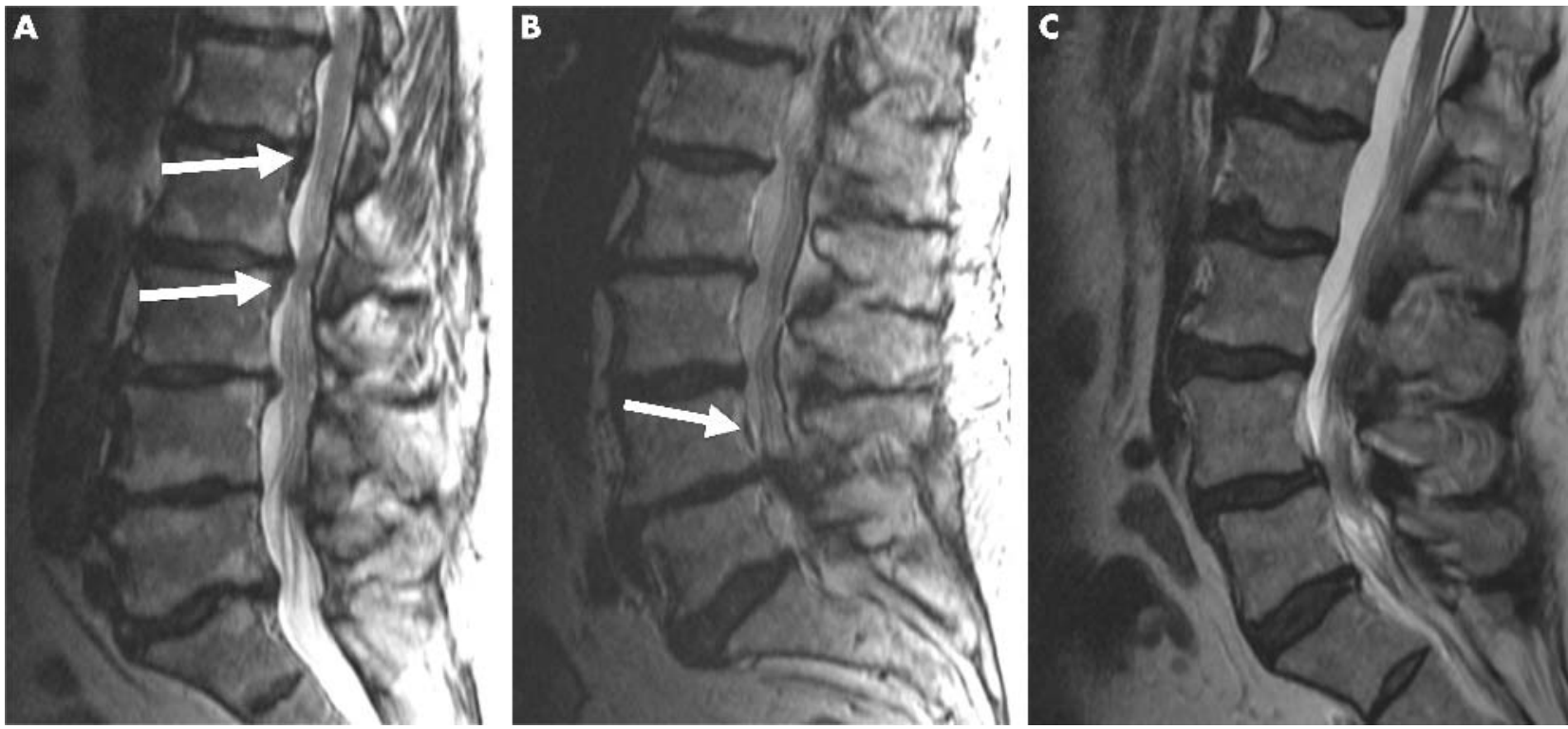

Figure $1 T_{2}$ weighted transaxial MRI scans (TR $6000 \mathrm{~ms} / \mathrm{TE} 105 \mathrm{~ms}$ ) of probands 2 (A), 10 (B), and 23 (C). (A) A hypertrophic band is seen at the L2-3 disc level and caudally at L3-4 (white arrows). Both disc and end plate degeneration are seen at all lumbar levels. (B) The scan shows OPLL at the L4 vertebral level (white arrow). This proband also had severe disc and end plate degeneration at multiple lumbar levels. (C) The scan indicates severe disc degeneration at multiple lumbar levels, and a Schmorl's node at L2-3.

splicing of intron 26, leading to an insertion of 88 extra nucleotides, and thus of 21 new amino acids, followed by a premature stop codon. The proband's 33 year old son and 87 year old mother were clinically unaffected and did not carry the mutation. The proband's father was not available for examination.

Proband 20 was heterozygous for the Trp2 allele. He had been previously operated on for a herniated nucleus pulposus, but also underwent a decompressive operation at a different level during the course of the present study. Probands 14, 26, and 27 were heterozygous for the Trp3 allele and proband 1 was homozygous for it.

An a to $t$ polymorphism in IVS6 ${ }^{-4}$ of COL11A2 has been reported to be associated with OPLL in the Japanese population. ${ }^{13}$ Even though OPLL is not a common cause of spinal stenosis in the Finnish population and was not a

\begin{tabular}{|c|c|c|c|c|c|c|c|c|}
\hline \multirow[b]{2}{*}{ Proband } & \multicolumn{2}{|c|}{ COL9A2 } & COL9A3 & \multirow[b]{2}{*}{$\begin{array}{l}\text { COL11AA2 } \\
\text { IVS6 }^{-4} a / t\end{array}$} & \multirow[b]{2}{*}{$\begin{array}{l}\text { AGC1 } \\
\text { VNTR* }^{*}\end{array}$} & \multirow[b]{2}{*}{$\begin{array}{l}\text { VDR } \\
2 T>C\end{array}$} & \multirow[b]{2}{*}{$\begin{array}{l}\text { VDR } \\
352 T>C\end{array}$} & \multirow[b]{2}{*}{$\begin{array}{l}\text { MMP-3, 5'-UTR - } \\
1171 \Delta a\end{array}$} \\
\hline & Trp2 & $\begin{array}{l}\text { IVS26 } \\
\text { a/c }\end{array}$ & Trp3 & & & & & \\
\hline 1 & $-1-$ & $-1-$ & $+/+$ & $t / t$ & $27 / 28$ & $\mathrm{FF}$ & $T t$ & $5 a / 6 a$ \\
\hline 2 & $-1-$ & $-1-$ & $-1-$ & $t / t$ & $28 / 28$ & $\mathrm{FF}$ & H & $5 a / 5 a$ \\
\hline 3 & $-1-$ & $-1-$ & $-1-$ & $t / a$ & $28 / 28$ & Ff & Tt & $5 a / 6 a$ \\
\hline 4 & $-1-$ & $-1-$ & $-1-$ & $t / t$ & $28 / 29$ & $\mathrm{FF}$ & $\Pi$ & $6 a / 6 a$ \\
\hline 5 & $-1-$ & $-1-$ & $-1-$ & $t / t$ & $28 / 28$ & $\mathrm{FF}$ & Tt & $5 a / 5 a$ \\
\hline 6 & $-1-$ & $-1-$ & $-1-$ & $t / t$ & $28 / 28$ & ff & $\mathrm{Tt}$ & $6 a / 6 a$ \\
\hline 7 & $-1-$ & $-1-$ & $-1-$ & $t / t$ & $28 / 28$ & $\mathrm{Ff}$ & $\pi$ & $6 a / 6 a$ \\
\hline 8 & $-1-$ & $-1-$ & $-1-$ & $t / t$ & $27 / 30$ & $\mathrm{Ff}$ & H & $6 a / 6 a$ \\
\hline 9 & $-1-$ & $-1-$ & $-1-$ & $t / t$ & $28 / 28$ & $\mathrm{FF}$ & Tt & $6 a / 6 a$ \\
\hline 10 & $-1-$ & $-1-$ & $-1-$ & $t / t$ & $27 / 28$ & ff & H & $5 a / 6 a$ \\
\hline 11 & $-1-$ & $-1-$ & $-1-$ & $t / t$ & $27 / 27$ & ff & $\Pi$ & $5 a / 6 a$ \\
\hline 12 & $-1-$ & $-1-$ & $-1-$ & $t / t$ & $27 / 29$ & $\mathrm{ff}$ & Tt & $5 a / 5 a$ \\
\hline 13 & $-1-$ & $-1-$ & $-1-$ & $t / t$ & $27 / 27$ & Ff & Tt & $5 a / 6 a$ \\
\hline 14 & $-1-$ & $-1-$ & $-/+$ & $t / t$ & $27 / 27$ & $\mathrm{FF}$ & $\Pi$ & $6 a / 6 a$ \\
\hline 15 & $-1-$ & $-1-$ & $-1-$ & $t / t$ & $25 / 28$ & Ff & Tt & $6 a / 6 a$ \\
\hline 16 & $-1-$ & $-1-$ & $-1-$ & $t / t$ & $27 / 28$ & $\mathrm{FF}$ & $\Pi$ & $5 a / 6 a$ \\
\hline 17 & $-1-$ & $-1-$ & $-1-$ & $t / a$ & $27 / 27$ & Ff & $\pi$ & $5 a / 6 a$ \\
\hline 18 & $-1-$ & $-1-$ & $-1-$ & $t / t$ & $28 / 28$ & ff & Tt & $6 a / 6 a$ \\
\hline 19 & $-1-$ & $-1-$ & $-1-$ & $t / t$ & $27 / 27$ & Ff & $\pi$ & $6 a / 6 a$ \\
\hline 20 & $-1+$ & $-1-$ & $-1-$ & $t / a$ & $28 / 28$ & $\mathrm{FF}$ & H & $5 a / 6 a$ \\
\hline 21 & $-1-$ & $-1-$ & $-1-$ & $t / t$ & $29 / 29$ & $\mathrm{FF}$ & $\pi$ & $5 a / 5 a$ \\
\hline 22 & $-1-$ & $-1-$ & $-1-$ & $t / t$ & $27 / 27$ & $\mathrm{Ff}$ & $\mathrm{Tt}$ & $5 a / 6 a$ \\
\hline 23 & $-1-$ & $-1+$ & $-1-$ & $t / t$ & $23 / 28$ & $\mathrm{FF}$ & Tt & $6 a / 6 a$ \\
\hline 24 & $-1-$ & $-1-$ & $-1-$ & $t / t$ & $27 / 27$ & $\mathrm{Ff}$ & $\Pi$ & $5 a / 6 a$ \\
\hline 25 & $-1-$ & $-1-$ & $-1-$ & $t / a$ & $28 / 28$ & ff & $\pi$ & $5 a / 6 a$ \\
\hline 26 & $-1-$ & $-1-$ & $-1+$ & $t / t$ & $27 / 27$ & $\mathrm{Ff}$ & H & $5 a / 5 a$ \\
\hline 27 & $-1-$ & $-1-$ & $-/+$ & $t / t$ & $28 / 28$ & Ff & H & $6 a / 6 a$ \\
\hline 28 & $-1-$ & $-1-$ & $-1-$ & $t / t$ & $29 / 29$ & $\mathrm{FF}$ & $\pi$ & $5 a / 6 a$ \\
\hline 29 & $-1-$ & $-1-$ & $-1-$ & $t / t$ & $28 / 28$ & Ff & $\pi$ & $6 a / 6 a$ \\
\hline
\end{tabular}




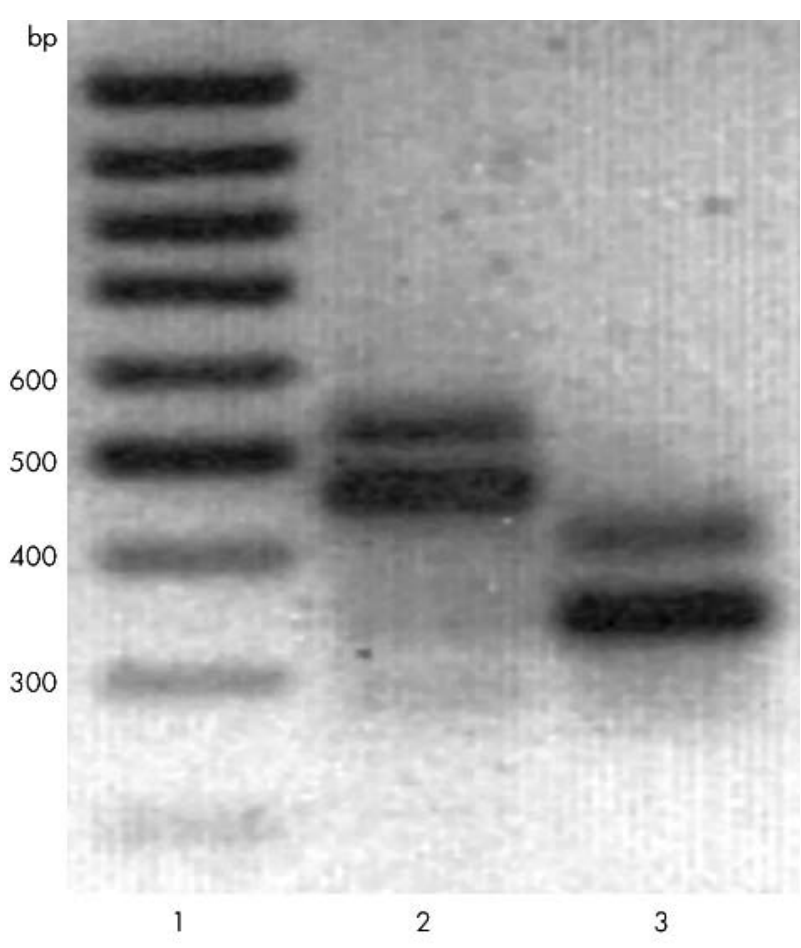

Figure 2 Agarose gel electrophoresis of $\alpha 2$ (IX) RT-PCR products. Total RNA from proband 23 was analysed by RT-PCR using primer pairs corresponding to exons 23 and 30 (lane 2), or exons 24 and 29 (lane 3 ), as indicated in "Materials and methods". The analysis showed two products of about $550 \mathrm{bp}$ and $460 \mathrm{bp}$ (lane 2) and $420 \mathrm{bp}$ and $340 \mathrm{bp}$ (lane 3). Sequencing indicated that the lower molecular weight products contained the wild-type sequence, whereas the higher molecular weight products also contained intron 26. Lane 1 contains a 100 bp ladder.

common finding among the probands (table 1), the possibility of an association between this polymorphism and stenosis was studied. The analysis showed that the frequency of the $t$ allele was $93.1 \%$ in the probands but only $72.3 \%$ in the control group $(p=0.0016$; tables 3 and 4$)$, although the genotype frequency differences were less significant $(p=0.0043)$. Based on this significant result (table 4), we wanted to see whether one of the genotypes exerts a dominant effect. Indeed, the t/a and a/a genotypes did not occur in significantly different proportions in the proband and control subjects while the $t / t$ genotype was found much more frequently in the probands than in the controls. Thus, we combined the t/a and a/a genotypes (4 probands, 28 controls) and contrasted it with the high risk $\mathrm{t} / \mathrm{t}$ genotype (25 probands, 28 controls, $p=0.0011)$. The significance of our finding of the high risk $t / t$ genotype (the "a" allele may also be viewed as protecting) may be expressed as the population attributable risk ${ }^{39}, \lambda=1.98-$ that is, the disease in an estimated $20 \%$ of the affected subjects in the population is attributable to the tt genotype.

Another polymorphism, exon $6^{+28} \mathrm{~A}>\mathrm{G}$, also reported previously, ${ }^{13}$ was found to be in complete linkage disequilibrium with the IVS6 ${ }^{-4} \mathrm{a}>\mathrm{t}$ polymorphism. The same authors have shown that the IVS6 ${ }^{-4}$ a allele is associated with skipping of exon 6 and retention of exon 7. We confirmed this finding here by performing an RT-PCR analysis on total lymphoblast RNA from proband 23, who was homozygous for the IVS $6^{-4} \mathrm{t}$ allele. The analysis showed only one fragment, and contained sequences for exon 6 (78 bp) and 7 (63 bp), but exon 8 ( $180 \mathrm{bp}$ ) was not present (not shown).

A number of sequence variations were detected in all collagen genes and AGCl, but they were likely to be neutral,
Table 4 Allele and genotype frequencies

\begin{tabular}{|c|c|c|}
\hline \multirow[b]{2}{*}{ Alleles and genotypes } & \multicolumn{2}{|l|}{ Frequencies (\%) } \\
\hline & Probands $(n=29)$ & Controls $(n=56)$ \\
\hline \multicolumn{3}{|l|}{ COL11A2 IVS6 ${ }^{-4}$} \\
\hline$t$ & 93.1 & 72.3 \\
\hline$a$ & 6.9 & 27.7 \\
\hline$t / t$ & 86.2 & 50.0 \\
\hline$t / a$ & 13.8 & 44.6 \\
\hline$a / a$ & 0 & 5.4 \\
\hline \multicolumn{3}{|l|}{ VDR $2 T>C$} \\
\hline$f$ & 41.4 & 32.1 \\
\hline $\mathrm{F}$ & 58.6 & 67.9 \\
\hline ff & 20.7 & 8.9 \\
\hline $\mathrm{Ff}$ & 41.4 & 46.4 \\
\hline $\mathrm{FF}$ & 37.9 & 44.6 \\
\hline \multicolumn{3}{|l|}{ VDR $352 T>C$} \\
\hline$t$ & 39.7 & 36.6 \\
\hline $\mathrm{T}$ & 60.3 & 63.4 \\
\hline H & 20.7 & 19.6 \\
\hline Th & 37.9 & 33.9 \\
\hline$\pi$ & 41.4 & 46.4 \\
\hline \multicolumn{3}{|l|}{ MMP-3 5 'UTR - $1171 \Delta a$} \\
\hline $5 a$ & 37.9 & 40.2 \\
\hline $6 a$ & 62.1 & 59.8 \\
\hline $5 a / 5 a$ & 17.2 & 14.3 \\
\hline $5 a / 6 a$ & 41.4 & 51.8 \\
\hline $6 a / 6 a$ & 41.4 & 33.9 \\
\hline
\end{tabular}

because they were found in equal frequencies in the controls (not shown).

\section{Southern analysis of the AGC1 VNTR}

An association between an AGCl VNTR polymorphism and LDD has been reported previously, in a study that suggested an overrepresentation of alleles with small numbers of the repeats in subjects with multilevel disc degeneration. ${ }^{17}$ Because disc degeneration is a common cause of stenosis and was present in all the probands, the VNTR polymorphism was analysed here (table 2). The alleles with 27 and 28 repeats were found to be the most common in both the stenosis (table 3) and the control group (not shown), and there were no significant differences in allele frequencies between the two groups.

\section{VDR and MMP-3 polymorphisms}

Two VDR polymorphisms reported to be associated with disc degeneration were studied: FokI and TaqI. FokI restriction enzyme digestion of exon 2 of VDR showed that the frequency of the $f$ allele was $41 \%$ in the probands and $32 \%$ in the controls (tables 3 and 4), a difference that was not significant $(p=0.24)$, while the allele frequencies for TaqI polymorphism likewise did not differ significantly between the proband and control groups (tables 3 and 4).

The $5 a / 5 a$ and $5 a / 6 a$ genotypes of the MMP-3 promoter region have been reported to be associated with intervertebral disc degeneration. ${ }^{21}$ No significant differences were found in the allelic frequencies or genotype distributions between the probands and controls (tables 3 and 4).

\section{Haplotype analysis}

Of the 16 possible haplotypes at the four sites, 13 (almost all) were observed in these data, which indicated a weak association between the sites (linkage disequilibrium). The haplotype frequencies did not differ significantly between the probands and controls $(\mathrm{p}=0.076)$.

\section{DISCUSSION}

LSS is common and one of the most clinically important spinal disorders. ${ }^{78}$ Because a number of genetic factors have 
been implicated in disc herniation, disc degeneration, and OPLL, which are the leading causes of degenerative stenosis, ${ }^{6}{ }^{13} 40$ we investigated possible associations between the previously identified genetic factors and degenerative LSS, and also analysed nine genes encoding intervertebral disc matrix proteins for sequence variations.

An association has been reported between OPLL and the COL11A2 IVS6 ${ }^{-4} \mathrm{t}$ allele in the Japanese population. ${ }^{6{ }^{13}{ }^{41}}$ The present screening of all exons and boundaries of COL1 $1 \mathrm{~A} 2$ for mutations in probands with LSS did not identify any unique sequence variations or putative causative mutations, but the frequency of the IVS6 ${ }^{-4}$ t allele was found to be $93.1 \%$ in the probands compared with $72.3 \%$ in the controls $(p=0.0016)$. The corresponding allele frequencies for OPLL positive and negative subjects reported by Koga et al were $86 \%$ and $74 \%{ }^{6}$ Thus our results further strengthen the hypothesis of a role for COL11A2 in stenosis, and also suggest that the IVS6 ${ }^{-4} \mathrm{t}$ allele can predispose carriers to degenerative LSS, which is not commonly associated with OPLL. It is not clear, however, by what mechanism this predisposition operates. COL11A2 exons 6 to 8 undergo complex alternative splicing, and Maeda et al have shown that the IVS6 ${ }^{-4}$ a allele is associated with a different splice pattern from the $t$ allele, exon 6 being skipped in its presence. ${ }^{13}$ Our present observations are in agreement with this finding. In addition to the inclusion of exon 6 , we showed here that exon 8 was skipped in the presence of the $t$ allele. Because any nucleotide can be found at position -4 in the acceptor splice site $^{42}$ the causal relationship between the alternatively spliced forms and the two alleles is not obvious, and, possibly, the factor responsible for the observed splice variants is either exon $6^{+28} \mathrm{~A}>\mathrm{G}$ polymorphism, which is in complete linkage disequilibrium with the IVS6 ${ }^{-4} \mathrm{a}>\mathrm{t}$ polymorphism, or another, yet unidentified variation.

A role for collagen IX in spinal disorders is supported by human $^{14}{ }^{15}$ and animal studies. ${ }^{43} 44$ Further evidence is presented in our study. One of the present probands, a subject with a history of LDD, had the Trp2 allele and four had the Trp3 allele. Because LDD is a common cause of LSS, it is possible that these alleles also predispose its carriers to stenosis. In the light of our previous findings, it is not likely that the Trp3 allele alone will lead to LSS, but it may be one of the predisposing factors. In addition, the analysis identified a heterozygous a to c mutation in $\operatorname{IVS}^{2} 6^{-2}$ of COL9A2. The mutation prevented splicing of intron 26 and resulted in an insertion of 21 new amino acids followed by a premature translation termination that was derived from intron 26. It is predicted that this mutation will result in synthesis of a truncated $\alpha 2$ (IX) chain that lacks the Cterminal end required for the assembly of the collagen IX heterotrimer of three $\alpha$ chains; the mutation is likely to lead to a reduced amount of collagen IX in the tissue. This is the first report of a splicing mutation in collagen IX leading to a premature translation termination and affecting the C-terminal end of the molecule.

Several predisposing genetic factors have been identified in disc degeneration. One of them is the VNTR polymorphism in AGCl. This is located in the chondroitin sulphate binding region (CS1), which is composed of repeated sequences of 57 nucleotides or 19 amino acids, the number of repeats varying from 13 to $33 .{ }^{31}$ It has recently been shown that subjects with a small number of repeats have an increased risk of disc degeneration, presumably because aggrecan molecules with fewer CS chains will have a poorer ability to hydrate the disc. ${ }^{17}$ No association between the VNTR polymorphism and LSS was found here, however, nor was any found between LSS and the VDR and MMP-3 polymorphisms, which have also been implicated in disc degeneration..$^{18-21}$ These findings suggest that disc degeneration is highly heterogeneous both clinically and genetically, and that leading to spinal stenosis may represent a distinct subgroup.

The genes coding for collagens I and II, which are the major intervertebral disc components, were also analysed. Mutations in these genes are known to cause a variety of osteochondrodysplasias, ${ }^{45}$ but their role in spinal diseases has not been investigated previously. The analysis did not provide any evidence that sequence variations in these genes are associated with spinal stenosis.

Despite the small sample size this study provides evidence that genetic factors are important in the causation of LSS. However, a larger population sample is needed to confirm these preliminary findings.

\section{ACKNOWLEDGEMENTS}

We thank Ms Aira Harju (Collagen Research Unit, Biocentre and Department of Medical Biochemistry and Molecular Biology, Oulu, Finland), Mr Hannu Hietala, Ms Christina L Troxell, and Ms Jaana Väisänen (Center for Gene Therapy and Department of Medicine, Tulane University Health Sciences Center, New Orleans, Louisiana, USA) for their expert technical assistance.

This work was supported by grants from the National Institute of Health (AR45982 to L A-K, HG00008 to JO), the Academy of Finland, the Louisiana Gene Therapy Research Consortium (New Orleans, LA) and HCA-The Health Care Company (Nashville, TN) (to LA-K).

\section{Authors' affiliations}

N Noponen-Hietala, M Männikkö, L Ala-Kokko, Collagen Research Unit, Biocentre and Department of Medical Biochemistry and Molecular Biology, University of Oulu, Oulu, Finland

E Kyllönen, Department of Physical Medicine and Rehabilitation, Oulu University Hospital, Oulu, Finland

E Ilkko, Department of Radiology, Oulu University Hospital, Oulu, Finland

J Karppinen, Finnish Institute of Occupational Health, Helsinki, Finland J Ott, Laboratory of Statistical Genetics, Rockefeller University, New York, NY, USA

L Ala-Kokko, Center for Gene Therapy and Department of Medicine, Tulane University Health Sciences Center, New Orleans, Louisiana, USA

\section{REFERENCES}

1 Arnoldi CC, Brodsky AE, Cauchoix J, Crock HV, Dommisse GF, Edgar MA, et al. Lumbar spinal stenosis and nerve root entrapment syndromes. Definition and classification. Clin Orthop 1976;115:4-5

2 Wynne-Davies R, Walsh WK, Gormley J. Achondroplasia and hypochondroplasia. Clinical variation and spinal stenosis. J Bone Joint Surg Br 1981;63:508-15.

3 Spivak JM. Degenerative lumbar spinal stenosis. J Bone Joint Surg Am 1998;80:1053-66.

4 Francomano CA, Muenke M. Craniosynostosis syndromes and skeletal dysplasias caused by mutations in fibroblast growth factor receptor genes. In: Royce PM, Steinmann B, eds. Connective tissue and its heritable disorders. Molecular, genetic and medical aspects. New York: Wiley-Liss, 2002:961-91.

5 Matsunaga S, Sakou T. Epidemiology of ossification of the posterior longitudinal ligament. In: Yonenobu K, Sakou T, Ono K, eds. Ossification of the posterior longitudinal ligament. Tokyo: Springer, 1997:11-17.

6 Koga H, Sakou T, Taketomi E, Hayashi K, Numasawa T, Harata S, et al. Genetic mapping of ossification of the posterior longitudinal ligament of the spine. Am J Hum Genet 1998;62:1460-7.

7 Casey PJ, Weinstein JN. Low back pain. In: Ruddy S, Harris ED Jr, Sledge CB, eds. Kelley's textbook of rheumatology. Philadelphia: Saunders, 2001:509-23.

8 Sheehan JM, Shaffrey Cl, Jane JA Jr. Degenerative lumbar stenosis: the neurosurgical perspective. Clin Orthop 2001;384:61-74.

9 Hall S, Bartleson JD, Onofrio BM, Baker HL Jr, Okazaki H, O'Duffy JD. Lumbar spinal stenosis. Clinical features, diagnostic procedures, and results of surgical treatment in 68 patients. Ann Intern Med 1985;103:271-5.

10 Spengler DM. Degenerative stenosis of the lumbar spine. J Bone Joint Surg Am 1987:69:305-8.

11 Porter RW. Spinal stenosis and neurogenic claudication. Spine 1996;21:2046-52.

12 Varughese G, Quartey GR. Familial lumbar spinal stenosis with acute disc herniations. Case reports of four brothers. J Neurosurg 1979:51:234-6.

13 Maeda S, Ishidou Y, Koga H, Taketomi E, Ikari K, Komiya S, et al. Functional impact of human collagen $\alpha 2(\mathrm{XI})$ gene polymorphism in pathogenesis of ossification of the posterior longitudinal ligament of the spine. J Bone Miner Res $2001 ; 16: 948-57$ 
14 Annunen S, Paassilta P, Lohiniva J, Perälä M, Pihlajamaa T, Karppinen J, et al. An allele of COL9A2 associated with intervertebral disc disease. Science 1999;285:409-12.

15 Paassilta $\mathbf{P}$, Lohiniva J, Göring HHH, Perälä M, Räinä SS, Karppinen J, et al. Identification of a novel common genetic risk factor for lumbar disk disease. JAMA 2001;285:1843-9.

16 Watanabe H, Nakata K, Kimata K, Nakanishi I, Yamada Y. Dwarfism and age-associated spinal degeneration of heterozygote $\mathrm{cmd}$ mice defective in aggrecan. Proc Natl Acad Sci USA 1997;94:6943-7.

17 Kawaguchi Y, Osada R, Kanamori M, Ishihara H, Ohmori K, Matsui H, et al. Association between an aggrecan gene polymorphism and lumbar disc degeneration. Spine 1999;24:2456-60.

18 Videman T, Leppävuori J, Kaprio J, Battie MC, Gibbons LE, Peltonen L, et al. Intragenic polymorphisms of the vitamin $D$ receptor gene associated with intervertebral disc degeneration. Spine 1998;23:2477-85.

19 Jones G, White C, Sambrook P, Eisman J. Allelic variation in the vitamin D receptor, lifestyle factors and lumbar spinal degenerative disease. Ann Rheum Dis 1998; 57:94-9.

20 Videman T, Gibbons LE, Battie MC, Maravilla K, Vanninen E, Leppävuori J, et al. The relative roles of intragenic polymorphisms of the vitamin $D$ receptor gene in lumbar spine degeneration and bone density. Spine 2001 26.E7-12.

21 Takahashi M, Haro H, Wakabayashi Y, Kawa-uchi T, Komori H, Shinomiya K. The association of degeneration of the intervertebral disc with $5 \mathrm{a} / 6 \mathrm{a}$ polymorphism in the promoter of the human matrix metalloproteinase- 3 gene. $J$ Bone Joint Surg Br 2001;83:491-5.

22 Modic MT, Steinberg PM, Ross JS, Masaryk TJ, Carter JR. Degenerative disk disease: assessment of changes in vertebral body marrow with MR imaging. Radiology 1988;166:193-9.

23 Körkkö J, Ala-Kokko L, De Paepe A, Nuytinck L, Earley J, Prockop DJ. Analysis of the COL1A1 and COL1A2 genes by PCR amplification and scanning by conformation-sensitive gel electrophoresis identifies only COLIA1 mutations in 15 patients with osteogenesis imperfecta type I: identification of common sequences of null-allele mutations. Am J Hum Genet 1998:62:98-110.

24 Ala-Kokko L, Kvist AP, Metsäranta M, Kivirikko KI, de Crombrugghe B, Prockop DJ, et al. Conservation of the sizes of 53 introns and over 100 intronic sequences for the binding of common transcription factors in the human and mouse genes for type II procollagen (COL2A1). Biochem J 1995; 15:923-9.

25 Pihlajamaa T, Vuoristo MM, Annunen S, Perälä M, Prockop DJ, Ala-Kokko L. Human COL9A1 and COL9A2 genes. Two genes of 90 and $15 \mathrm{~kb}$ code for similar polypeptides of the same collagen molecule. Matrix Biol 1998; 17:237-41.

26 Paassilta P, Pihlajamaa T, Annunen S, Brewton RG, Wood BM, Johnson CC, et al. Complete sequence of the 23-kilobase human COL9A3 gene. Detection of Gly-X-Y triplet deletions that represent neutral variants. J Biol Chem 1999;274:22469-75.

27 Annunen S, Körkkö J, Czarny M, Warman ML, Brunner HG, Kääriäinen H, et al. Splicing mutations of 54-bp exons in the COL1 1A1 gene cause Marshall syndrome, but other mutations cause overlapping Marshall/Stickler phenotypes. Am J Hum Genet 1999;65:974-83.

28 Vuoristo MM, Pihlajamaa T, Vandenberg P, Prockop DJ, Ala-Kokko L. The human COL11A2 gene. The structure indicates that the gene has not evolved with the genes for the major fibrillar collagens. J Biol Chem 1995:270:22873-81.
29 Doege KJ, Sasaki M, Kimura T, Yamada Y. Complete coding sequence and deduced primary structure of the human cartilage large aggregating proteoglycan, aggrecan. Human-specific repeats, and additional alternatively spliced forms. J Biol Chem 1991;266:894-902.

30 Valhmu WB, Palmer GD, Rivers PA, Ebara S, Cheng JF, Fischer S, et al. Structure of the human aggrecan gene: exon-intron organisation and association with the protein domains. Biochem J 1995;309:535-42.

31 Doege KJ, Coulter SN, Meek LM, Maslen K, Wood JG. A human-specific polymorphism in the coding region of the aggrecan gene. Variable number of tandem repeats produce a range of core protein sizes in the general population. J Biol Chem 1997;272:13974-9.

32 Morrison NA, Qi JC, Tokita A, Kelly PJ, Crofts L, Nguyen TV, et al. Predictor of bone density from vitamin $D$ receptor alleles. Nature 1994;367:284-7.

33 Saijo $T$, Ito $M$, Takeda E, Huq AH, Naito E, Yokota I, et al. A unique mutation in the vitamin $D$ receptor gene in three Japanese patients with vitamin D dependent rickets type II: utility of single-strand conformation polymorphism analysis for heterozygous carrier detection. Am J Hum Genet 1991:49:668-73

34 Ye S, Watts GF, Mandalia S, Humphries SE, Henney AM. Preliminary report: genetic variation in the human stromelysin promoter is associated with progression of coronary atherosclerosis. Br Heart J 1995;73:209-15.

35 Körkkö J, Annunen S, Pihlajamaa T, Prockop DJ, Ala-Kokko L. Conformation sensitive gel electrophoresis for simple and accurate detection of mutations: comparison with denaturing gradient gel electrophoresis and nucleotide sequencing. Proc Natl Acad Sci USA 1998;95:1681-5.

36 Gross C, Eccleshall TR, Malloy PJ, Villa ML, Marcus R, Feldman D. The presence of a polymorphism at the translation initiation site of the vitamin $D$ receptor gene is associated with low bone mineral density in postmenopausal Mexican-American women. J Bone Miner Res 1996;11:1850-5.

37 Harris SS, Eccleshall TR, Gross C, Dawson-Hughes B, Feldman D. The vitamin $D$ receptor start codon polymorphism (Fokl) and bone mineral density in premenopausal American black and white women. J Bone Miner Res 1997:12:1043-8.

38 Chiano MN, Clayton DG. Fine genetic mapping using haplotype analysis and the missing data problem. Ann Hum Genet 1998;62:55-60.

39 Armitage P, Berry G. Statistical methods in medical research. Oxford, UK Blackwell, 1988.

40 Ala-Kokko L. Genetic risk factors for lumbar disc disease. Ann Med 2002;34:42-7.

41 Numawasa T, Koga H, Ueyama K, Maeda S, Sakou T, Harata S, et al. Human retinoic $\mathrm{X}$ receptor $\beta$ : complete genomic sequence and mutation search for ossification of posterior longitudinal ligament of the spine. J Bone Miner Res 1999:14:500-8.

42 Cartegni L, Chew SL, Krainer AR. Listening to silence and understanding nonsense: exonic mutations that affect splicing. Nat Rev Genet 2002:3:285-98.

43 Nakata K, Ono K, Miyazaki J-I, Olsen BR, Muragaki Y, Adachi E, et al. Osteoarthritis associated with mild chondrodysplasia in transgenic mice expressing $\alpha 1(\mathrm{IX})$ collagen chains with a central deletion. Proc Natl Acad Sci USA 1993;90:2870-4.

44 Kimura T, Nakata K, Tsumaki N, Miyamoto S, Ebara S, Ochi T. Progressive degeneration of articular cartilage and intervertebral discs. An experimental study in transgenic mice bearing a type IX collagen mutation. Int Orthop 1996;20:177-81

45 Myllyhariu J, Kivirikko KI. Collagens and collagen-related diseases. Ann Med 2001;33:7-21. 